Check for updates

Cite this: RSC Adv., 2017, 7, 38902

\title{
Molecular recognition with cyclodextrin polymer: a novel method for removing sulfides efficiently $\dagger$
}

\author{
Linlin Li, Zunbin Duan, Jinshe Chen, Yulu Zhou, Lijun Zhu, Yuzhi Xiang \\ and Daohong Xia (D)*
}

A series of cyclodextrin polymers (CDPs) were synthesized and they were used for removing different sulfides by molecular recognition. Different CDPs showed a higher desulfurization efficiency for sulfides with an aromatic ring structure than those with an aliphatic chain structure. For different cyclodextrin polymers, $\beta$-CDP has a more suitable cavity size for removing DBT. Moreover, it has a good synergetic effect of adjacent cyclodextrin cavities and good electronic interactions with DBT. For these reasons, $\beta$-CDP showed the best desulfurization performance, in particular it has good performance for deep desulfurization by forming inclusion complexes and excellent selectivity for removing DBT. Meanwhile, the $\beta$-CDP showed good regeneration performance. Various characterization measurements were used to characterize the $\beta$-CDP before and after desulfurization of DBT, the results of which showed that it had advantages of wide application temperature range and good structure stability before and after desulfurization. Finally, a molecular recognition mechanism for removing sulfides efficiently was proposed.

Received 18th June 2017 Accepted 30th July 2017

DOI: $10.1039 / \mathrm{c} 7 \mathrm{ra0} 6782 \mathrm{~h}$

rsc.li/rsc-advances compounds in molecular recognition, owing to the coexistence of hydrophobic cavity and hydrophilic surface in them, have showed good performance and already been widely used in drug delivery, ${ }^{32,33}$ separation, ${ }^{34,35}$ catalysis, ${ }^{36}$ as well as desulfurization..$^{37-39}$ However, cyclodextrins have rather small binding constants with substrates, ${ }^{40}$ and the binding abilities for them couldn't be improved effectively by functionalization and modification, ${ }^{41}$ limitating the application of them in molecular recognition. Fortunately, these problems have been solved by the bridged cyclodextrin in some degree. ${ }^{42}$ Two adjacent cyclodextrin cavities exist in them, which could act synergistically when bridged cyclodextrins interact with substrates. These bridged cyclodextrins can not only strengthen interactions between host and guest, but also improve the selectivity in molecular recognition process. ${ }^{\mathbf{4 3}-48}$ Cyclodextrin polymers as a novel kind of bridged cyclodextrins, each molecule of the polymer has more cyclodextrin cavities, probably indicating a potentially stronger synergy. In addition, cyclodextrin cavities have certain sizes. The strong synergy and cavities with certain sizes in cyclodextrin polymers may make cyclodextrin polymers play a significant part in selective and deep desulfurization.

In view of those challenges in the removal of DBT by traditional desulfurization process and the unique properties owned by cyclodextrin polymers, in this paper, the cyclodextrin polymers were introduced in desulfurization process by molecular recognition method. What is more, it is obvious that the cyclodextrin polymers are much more environmental friendly as a novel biobased material and lower costs than traditional desulfurizers.
State Key Laboratory of Heavy Oil Processing, China University of Petroleum, Qingdao 266580, People's Republic of China. E-mail: xiadh@upc.edu.cn

$\dagger$ Electronic supplementary information (ESI) available. See DOI: $10.1039 / \mathrm{c} 7 \mathrm{ra} 06782 \mathrm{~h}$ 
To investigate the desulfurization performance of cyclodextrin polymers based on molecular recognition, a series of cyclodextrin polymers were synthesized and then used to remove different sulfides in $n$-heptane. Desulfurization conditions, deep desulfurization performance, regeneration, selectivity of the chosen desulfurizer were investigated systematically. The structural changes of cyclodextrin polymer before and after desulfurization were confirmed by XRD, ${ }^{1} \mathrm{H}$ NMR, FTIR and $\mathrm{N}_{2}$ adsorption and desorption isotherms. Based on those results, the mechanism of desulfurization by molecular recognition of cyclodextrin polymers was studied.

\section{Experimental}

\subsection{Materials}

Alpha-cyclodextrin $(\alpha-\mathrm{CD})$, beta-cyclodextrin $(\beta-\mathrm{CD})$, gammacyclodextrin $\left(\gamma\right.$-CD) and potassium carbonate $\left(\mathrm{K}_{2} \mathrm{CO}_{3}\right)$ all with purites $>99 \%$, were purchased from Sinopharm Chemical Reagent Co. Ltd. Thiophene (Th), benzothiophene (BT), dibenzothiophene (DBT), $t$-butyl mercaptan (TBM), $n$-hexadecyl mercaptan (NHM), thiophenol (TP), diethyl sulfide (DES), tertbutyl sulfide (TBS), ethyl phenyl sulfide (EPS), diethyl disulfide (DEDS) all with analytical pure, and tetrafluoroterephthalonitrile (TFT, >99\%) were purchased from Merck-Schuchardt. Tetrahydrofuran (THF) and dimethyl formamide (DMF) with purites $>99 \%$, were also purchased from Sinopharm Chemical Reagent Co. Ltd. and trace water of them were removed by active alumina before use.

\subsection{Synthesis of cyclodextrin polymers}

$\beta$-Cyclodextrin polymer ( $\beta$-CDP) was synthesized following the procedure reported by Alaaeddin Alsbaiee et al. ${ }^{49}$ In a typical synthesis, $\beta$-CD $(2.00 \mathrm{~g}, 1.76 \mathrm{mmol})$, TFT (1.00 g, 5 $\mathrm{mmol})$, and $\mathrm{K}_{2} \mathrm{CO}_{3}(3.00 \mathrm{~g}, 21.7 \mathrm{mmol})$ were added into a flask equipped with a magnetic stir bar, and the flask was purged with $\mathrm{N}_{2}$ for $5 \mathrm{~min}$. Then $80 \mathrm{~mL}$ dried THF/DMF $(8 / 1, \mathrm{v} / \mathrm{v})$ was added and purged by $\mathrm{N}_{2}$ for another $3 \mathrm{~min}$. The mixture was heated to $80{ }^{\circ} \mathrm{C}$ and stirred at $500 \mathrm{rpm}$ for $48 \mathrm{~h}$. After that, the suspension was filtered and washed by $1 \mathrm{~mol} \mathrm{~L}^{-1} \mathrm{HCl}$ to remove residual $\mathrm{K}_{2} \mathrm{CO}_{3}$. The residual solid was soaked in $100 \mathrm{~mL} \mathrm{H}_{2} \mathrm{O}$ for $15 \mathrm{~min}$ twice, $100 \mathrm{~mL}$ THF for $30 \mathrm{~min}$ twice and $150 \mathrm{~mL} \mathrm{CH}_{2} \mathrm{Cl}_{2}$ for $15 \mathrm{~min}$ once (after the process of soaking every time, the product was under the suction filtration).

Finally, $\beta$-CDP was obtained as a light yellow powder dried at RT for 2-3 days under vacuum. $\alpha$-Cyclodextrin polymer ( $\alpha$-CDP) as a grass-green powder and $\gamma$-cyclodextrin polymer $(\gamma$-CDP) as a light yellow powder were also synthesized following the procedure described above. And then, mixed polymer with $\beta$ cyclodextrin and $\gamma$-cyclodextrin $((\beta \& \gamma)-\mathrm{CDP})$ was synthesized. $\beta$ $\mathrm{CD}$ and $\gamma$-CD were added with the molar ratio of $1: 1$. Then the same amount of other materials was added and identical procedure was conducted as above. Finally, $(\beta \& \gamma)$-CDP was obtained as a light yellow color powder.

\subsection{Characterization}

Fourier transform infrared (FTIR) spectra of CDs, CDPs and TFT were carried out by a Nicolet 6700 FTIR spectrometer using $\mathrm{KBr}$ technique. X-ray diffraction pattern (XRD) was recorded by a Panalytical X'Pert Pro MPD diffractometer (Netherlands) with $\mathrm{Cu} \mathrm{K} \alpha$ radiation $(\lambda=0.15406 \mathrm{~nm})$ to confirm the crystalline structure of different samples. Thermogravimetric analysis (TG) was used to confirm the structural changes of samples with temperature, and the sample was heated in alumina crucibles from room temperature to $700{ }^{\circ} \mathrm{C}$ at a rate of $10^{\circ} \mathrm{C} \mathrm{min}^{-1}$ under high purity nitrogen. Specific surface area was calculated using the Brunauer, Emmet and Teller (BET) isotherm and the pore volume was calculated using the Barrett-Joiner-Halenda method. ${ }^{13} \mathrm{C}$ solid-state NMR was used to confirm the structures of CDPs, and ${ }^{1} \mathrm{H}$ NMR was used to confirm the structures of $\beta$ CDP before and after desulfurization.

\subsection{Desulfurization experiments}

In order to investigate the desulfurization performances exhibited by different CDPs, a variety of sulfides with approximately $100 \mu \mathrm{g} \mathrm{g}^{-1}$ sulfur content were prepared by dissolving DBT, BT (benzothiophene), Th (thiophene), TBM ( $t$-butyl mercaptan), TP (thiophenol), DES (diethyl sulfide), TBS (tert-butyl sulfide), EPS (ethyl phenyl sulfide) and DEDS (diethyl disulfide) in $n$-heptane, respectively. And mixed sulfides in $n$-heptane including DBT $\left(60 \mu \mathrm{g} \mathrm{g}^{-1}\right)$, NHM ( $n$-hexadecyl mercaptan, $20 \mu \mathrm{g} \mathrm{g}^{-1}$ ), TBS $\left(20 \mu \mathrm{g} \mathrm{g}^{-1}\right)$, was also prepared to evaluate the desulfurization selectivity of cyclodextrin polymer.

The desulfurization experiments were performed as follows. CDP powder was firstly added in an Erlenmeyer flask equipped with a stirring magneton, and then $n$-heptane solution of sufides was added into the flask with the mass ratio of CDP to sulfide solution controlled as $1: 40$. Meanwhile the desulfurization temperature was maintained at $25 \pm 0.2{ }^{\circ} \mathrm{C}$. With stirring, the desulfurization process was carried out and the sample was taken out at different time intervals. The sulfur content of sulfide solution was analyzed by ANTEK9000 NS analyzer (USA), and the desulfurization efficiency was calculated according to the following equation.

$$
\begin{aligned}
& Y=100 \%\left(C_{0}-C_{t}\right) V / C_{0} V \\
& Q=\left(C_{0}-C_{t}\right) V \times 10^{-3} / A
\end{aligned}
$$

where $Y$ is the desulfurization efficiency, $V(\mathrm{~mL})$ is the volume of $n$-heptane solution of sufides, $C_{0}\left(\mu \mathrm{g} \mathrm{mL}{ }^{-1}\right)$ is the initial sulfur concentration of $n$-heptane solution of sufides, and $C_{t}$ $\left(\mu \mathrm{g} \mathrm{mL} \mathrm{m}^{-1}\right.$ ) is the sulfur concentration of $n$-heptane solution of sufides at desulfurization time $t(\mathrm{~min}), Q\left(\mathrm{mg} \mathrm{g}^{-1}\right)$ is the sulfur adsorption capacity, $A(\mathrm{~g})$ is the mass of the adsorbent.

\section{Results and discussion}

\subsection{Characterization of cyclodextrin polymers}

FTIR spectra of TFT, CDs, and CDPs were showed in Fig. 1 to confirm structures of synthesized samples. It could be seen 


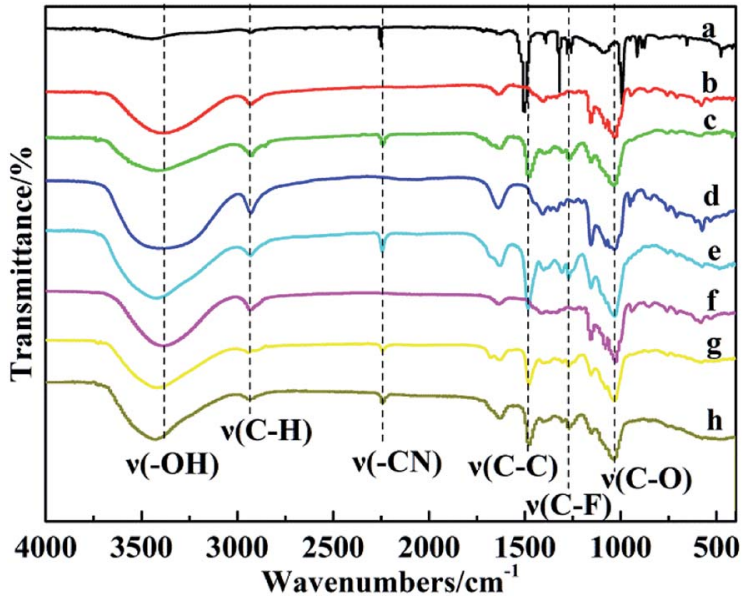

Fig. 1 FTIR spectra of (a) TFT, (b) $\beta$-CD, (c) $\beta$-CDP, (d) $\alpha$-CD, (e) $\alpha$ CDP, (f) $\gamma-C D$, (g) $\gamma$-CDP, (h) $(\beta \& \gamma)-C D P$.

that, different CDs had almost the same adsorption bands ascribed to the similar structures and functional groups owned by them. The broad adsorption band at $3300 \mathrm{~cm}^{-1}$, band near $2930 \mathrm{~cm}^{-1}$ and band at $1030 \mathrm{~cm}^{-1}$ was ascribed to $-\mathrm{OH}$ stretching vibration, $\mathrm{C}-\mathrm{H}$ aliphatic stretches and $\mathrm{C}-\mathrm{O}$ stretching vibration, respectively. For the CDPs, similar characteristic adsorption peaks mentioned above were all observed in them, indicating that the CDPs have many similar structures to CDs. However, there were some differences between CDs and the corresponding polymers. The biggest differences were the adsorption bands produced by nitrile stretch at $2235 \mathrm{~cm}^{-1}$, as well as, C-C aromatic stretches at $1670 \mathrm{~cm}^{-1}$ and $1463 \mathrm{~cm}^{-1}$ in polymers, which could be traced back to the bridging TFT. Besides, adsorption band at $1268 \mathrm{~cm}^{-1}$ in polymers, corresponding to stretching vibration of $\mathrm{C}-\mathrm{F},{ }^{50}$ was much weaker than that in TFT's spectrum, as expected for partial F substitution in CDPs.

The XRD patterns of TFT, CDs and CDPs were showed in Fig. 2. It's showed that the diffractogram of $\beta-\mathrm{CD}$ exhibited characteristic peaks at $2 \theta$ value of $18^{\circ}$ due to its crystalline nature. $^{51}$ While the synthesized $\beta$-CDP showed amorphous diffraction with several broad humps at around $2 \theta$ values of $12^{\circ}$

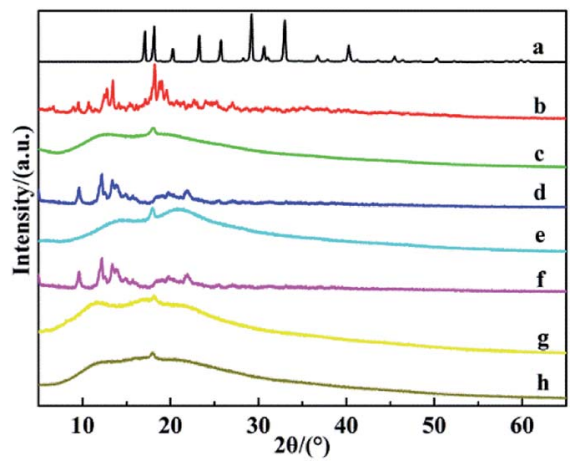

Fig. 2 XRD patterns of (a) TFT, (b) $\beta$-CD, (c) $\beta$-CDP, (d) $\alpha$-CD, (e) $\alpha$ CDP, (f) $\gamma-C D$, (g) $\gamma$-CDP, (h) $(\beta \& \gamma)-C D P$. and $18^{\circ}$, suggesting that new structures were formed. The result was consistent with that of FTIR and indicated that the crystallinity decreased dramatically after polymerization. And the reason could be ascribed to the condensation reaction of $\beta-C D$, in which the $\beta$-CD with crystalline structure converted to $\beta$-CDP with amorphous structure.

In addition, it could also be seen that the X-ray diffraction patterns of $\alpha$-CDP, $\gamma$-CDP and ( $\beta \& \gamma)$-CDP were similar to that of $\beta$-CDP and all showed amorphous diffractions with several broad humps, which also indicated that different CDPs were synthesized successfully.

Nitrogen adsorption and desorption isotherms for CDPs were presented in Fig. 3. Nitrogen adsorption and desorption isotherms of $\alpha$-CDP, $\beta$-CDP, $\gamma$-CDP, $(\beta \& \gamma)$-CDP could be classified as a type II isotherm, ${ }^{49}$ indicating the existence of mesoporosity in it. The main part of the hysteresis loops remained in the same relative pressure range restricted to a range of $P / P_{0}$ between 0 and 1.0. The surface area (BET) based on nitrogen adsorption of $\beta$-CDP was $156 \mathrm{~m}^{2} \mathrm{~g}^{-1}$. While the surface areas (BET) of other CDPs were all below $50 \mathrm{~m}^{2} \mathrm{~g}^{-1}$, which were relatively small.

Compared with other CDs, $\beta$-CD has a complete secondary belt is formed by circular hydrogen bonds in it. And the existence of complete secondary belt makes $\beta$-CD own a rather rigid structure, which leads to a very low solubility in water compared with other CDs. ${ }^{52,53}$ The special structure of $\beta$-CD is probably related with the high specific surface area of $\beta$-CDP compared with other CDPs.

The TG curves of CDPs were shown in Fig. S1, $\uparrow$ different CDPs had similar TG curves. The slow weight-loss step appeared at temperature below $200{ }^{\circ} \mathrm{C}$, which was generally assigned to the loss of water in the CDP sample. What is more, there was another peak appearing at about $300{ }^{\circ} \mathrm{C}$, which could be ascribed to that amorphous structure of the CDP began to decompose. Due to the high decomposition temperature for $\mathrm{CDP}$, it has the advantage of wide application temperature range, which could better meet practical demands.

${ }^{13} \mathrm{C}-\mathrm{NMR}$ was adopted to confirm the structures of CDPs. The results of ${ }^{13} \mathrm{C}-\mathrm{NMR}$ analysis of all CDPs were showed in Fig. S2. $\dagger$
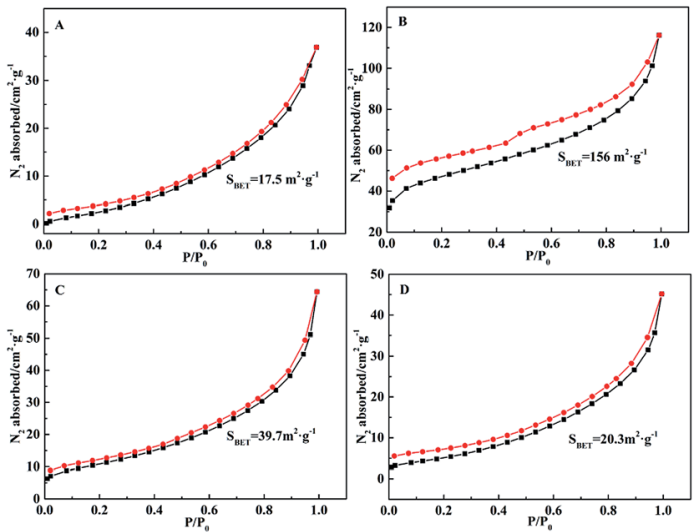

Fig. $3 \quad N_{2}$ adsorption and desorption isotherms of (A) $\alpha$-CDP, (B) $\beta$ CDP, (C) $\gamma$-CDP, (D) $(\beta \& \gamma)-C D P$. 
It could be seen that ${ }^{13} \mathrm{C}$ signals of other samples exhibited resonances at $\delta=72,100$ and $140 \mathrm{ppm}$, which are similar with those of $\beta$-CDP, as reported by Alsbaiee, etc. $^{49}$

\subsection{Desulfurization performances of different CDPs for different sulfides}

As we can see from Fig. 4, four different cyclodextrin polymers were used to remove different kinds of sulfides in $n$-heptane, including Th, BT, DBT, TBM and DES. For Th, BT and DBT, the sulfur removals all decreased in the same order as, $\beta$-CDP > $(\beta \& \gamma)$-CDP $>\gamma$-CDP. $\alpha$-CDP performed a little different, as exhibited that it showed a relatively low sulfur removal and needed long removal time to reach equilibrium. While other polymers could all reach equilibrium in a rather short time, and among those thiophene compounds listed above, $\beta$-CDP could always be the most efficient desulfurizer under the same condition. For other kinds of sulfides, such as TBM and DES mentioned in Fig. 4D and E owning same carbon numbers with Th, all those polymers performed much poorer, the sulfur removals hardly exceeded $12 \%$. This might be due to the efficient molecular recognition of $\beta$-CDP, which could be concluded that the $\beta$-CDP has more suitable cavity size for removing DBT by the inclusion effect. Taking all results discussed above into account, the $\beta$-CDP was chosen as the best desulfurizer.

Fig. 5 showed the desulfurization performances of $\beta$-CDP for sulfides with different structures. From the results of sulfides
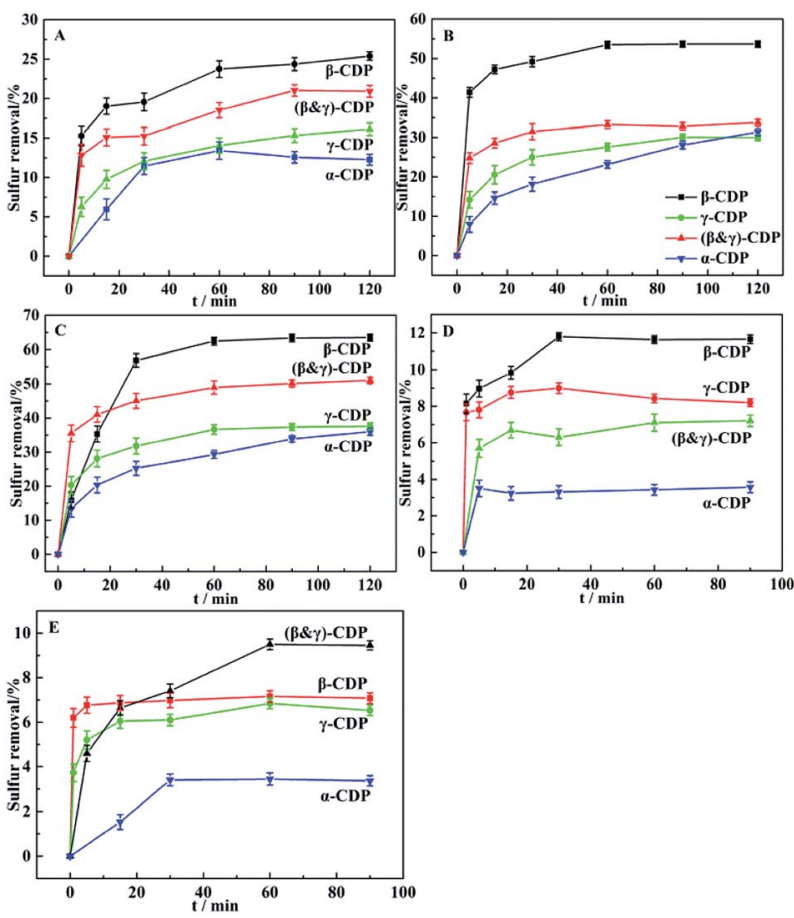

Fig. 4 Desulfurization performances of different CDPs for (A) Th, (B) $B T,(C)$ DBT, (D) TBM, (E) DES. Desulfurization conditions: temperature $=25^{\circ} \mathrm{C}$, time $=2 \mathrm{~h}$ or $1.5 \mathrm{~h}$, mass ratio of $\beta$-CDP to $n$-heptane solution of DBT is $1: 40$. All results were obtained in triplicate, and standard deviation is indicated by the error bars. with aromatic ring structure removal over $\beta$-CDP, it's could be seen that $\beta$-CDP exhibited the best desulfurization performance for DBT, and its desulfurization efficiency could reach $63 \%$. For the other sulfides, the removal percentage of them decreased in the order: BT $>$ TP $>$ EPS $>$ Th. As a comparison, the desulfurization rate of sulfides with aliphatic chain structure was much lower, and all below 12\%. Moreover, the removal percentage of these sulfides decreased in the order: TBM $>$ DEDS $>$ DES $>$ TBS. The reason for the results might lie in that the cavities of $\beta$-CDP have suitable size for DBT and the electron-deficient aromatic structures of $\beta$-CDP have good electrostatic interactions with the electron-rich aromatic structures of DBT. And the results may indicate that the size of $\beta$-CDP cavities and electrostatic effects between $\beta$-CDP and DBT play an important role in efficient molecular recognition.

\subsection{Effects of desulfurization conditions on desulfurization performance of $\boldsymbol{\beta}$-CDP for DBT}

Fig. 6A showed the effect of different temperatures on desulfurization for DBT. It could be clearly seen that as the desulfurization temperature rising, the removal efficiency decreased gradually and the proper temperature of removing DBT was $25{ }^{\circ} \mathrm{C}$ or room temperature, which suggested that DBT could be removed by $\beta$-CDP under very moderate temperature than other desulfurization methods. ${ }^{\mathbf{5 4 , 5 5}}$

In addition, the mass ratio of $\beta$-CDP to $n$-heptane solution of DBT was also investigated. As shown in Fig. 6B, it's obvious that the sulfur removal efficiency increased with the mass ratio of $\beta$ CDP to $n$-heptane solution of DBT increasing, while the sulfur adsorption capacity of $\beta$-CDP showed the opposite results. Considering two factors of sulfur removal efficiency and adsorption capacity, the appropriate mass ratio of $\beta$-CDP to $n$ heptane solution of DBT was about $1: 20$.

The desulfurization performance of $\beta$-CDP for DBT with different initial sulfur concentrations was showed in Fig. 7. It

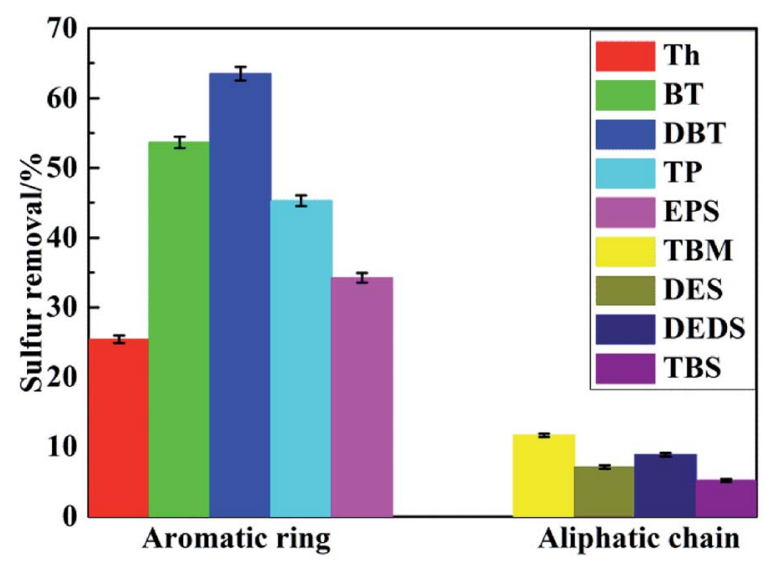

Fig. 5 Desulfurization performances of $\beta$-CDP for sulfides with aromatic ring structure and sulfides with aliphatic chain structure. Desulfurization conditions: temperature $=25^{\circ} \mathrm{C}$, time $=2 \mathrm{~h}$ or $1.5 \mathrm{~h}$, mass ratio of $\beta$-CDP to $n$-heptane solution of DBT is $1: 40$. All results were obtained in triplicate, and standard deviation is indicated by the error bars. 

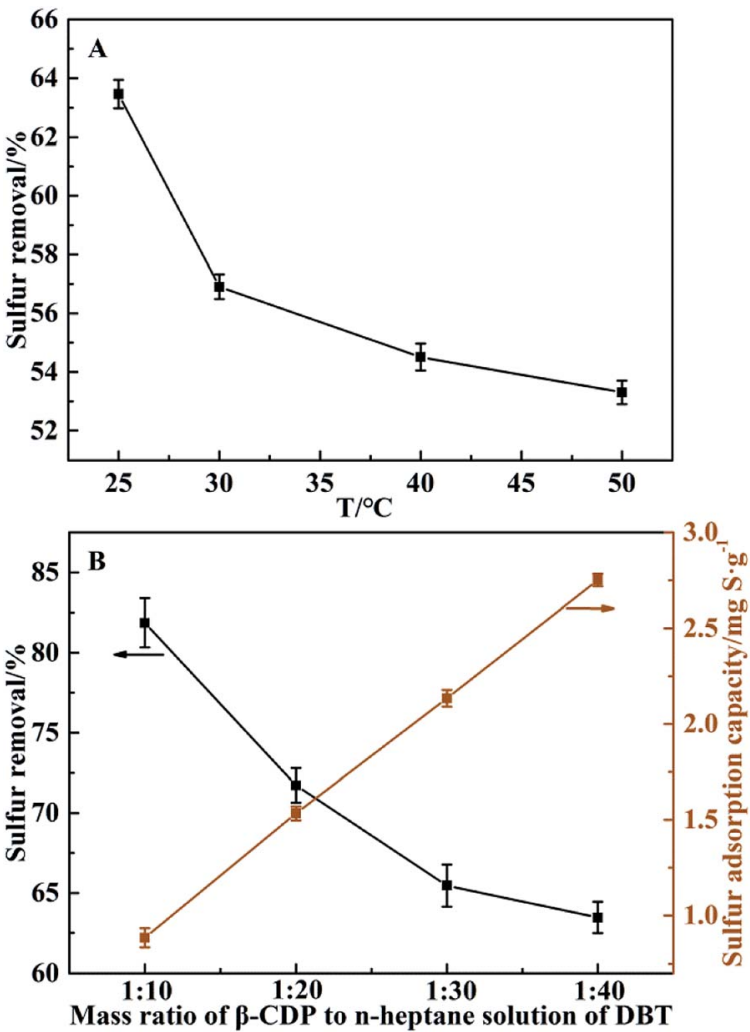

Fig. 6 Effects of (A) desulfurization temperature and (B) mass ratio of $\beta$-CDP to $n$-heptane solution of DBT on the desulfurization performance of $\beta$-CDP for DBT. All results were obtained in triplicate, and standard deviation is indicated by the error bars.

could be seen that the desulfurization efficiency increased with the decrease of initial sulfur content. For the DBT solution with $20 \mu \mathrm{g} \mathrm{g}^{-1}$ sulfur content, the desulfurization efficiency of $\beta$-CDP could reach $73 \%$ and the sulfur content of DBT solution could be reduced to $5.3 \mu \mathrm{g} \mathrm{g}^{-1}$ after desulfurization.

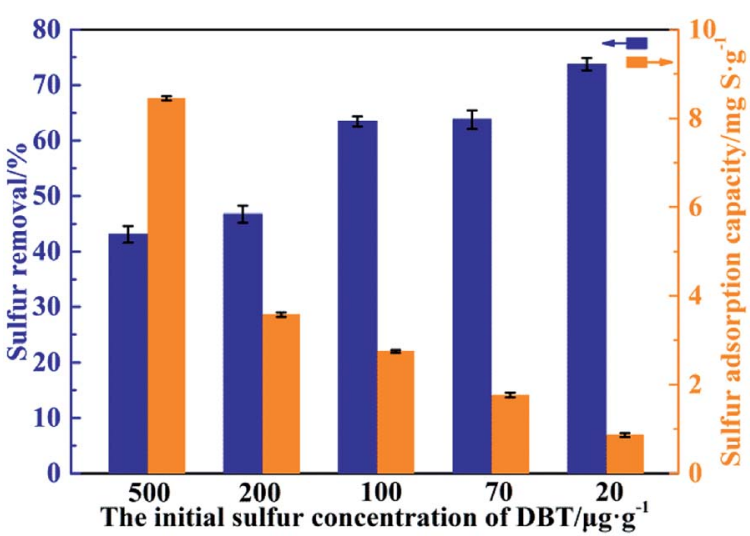

Fig. 7 Desulfurization performance of $\beta$-CDP for DBT with different initial sulfur concentration. Desulfurization conditions: temperature $=$ $25^{\circ} \mathrm{C}$, time $=2 \mathrm{~h}$, mass ratio of $\beta$-CDP to $n$-heptane solution of DBT is $1: 40$. All results were obtained in triplicate, and standard deviation is indicated by the error bars.
Table 1 Deep desulfurization performance of $\beta$-CDP for $\mathrm{DBT}^{a}$

\begin{tabular}{lll}
\hline $\begin{array}{l}\text { The initial sulfur } \\
\text { concentration } / \mu \mathrm{g} \mathrm{g}^{-1}\end{array}$ & $\begin{array}{l}\text { Sulfur } \\
\text { removal/\% }\end{array}$ & $\begin{array}{l}\text { Sulfur content after } \\
\text { desulfurization } / \mu \mathrm{g} \mathrm{g}^{-1}\end{array}$ \\
\hline 40 & 69.3 & 12.3 \\
30 & 70.3 & 8.9 \\
20 & 73.7 & 5.3 \\
10 & 73.9 & 2.6
\end{tabular}

${ }^{a}$ Desulfurization conditions: temperature $=25^{\circ} \mathrm{C}$, time $=2 \mathrm{~h}$, mass ratio of $\beta$-CDP to $n$-heptane solution of DBT is $1: 40$.

In order to better investigate the deep desulfurization performance of $\beta$-CDP for DBT, a series of desulfurization experiments were conducted and the result was summarized in Table 1.

As shown in Table 1, for the initial concentration of DBT solution below $30 \mu \mathrm{g} \mathrm{g}^{-1}$, the sulfur content could be reduced to $10 \mu \mathrm{g} \mathrm{g}^{-1}$ after desulfurization, which could better meet the demands of deep desulfurization. ${ }^{56,57}$ The result suggested that $\beta$-CDP has good performance for deep desulfurization. Because of the high synergetic effect of adjacent cyclodextrin cavities in $\beta$-CDP and electronic effect between $\beta$-CDP and DBT, DBT might be combined with cavities well in molecular recognition and promote the desulfurization performance.

\subsection{The desulfurization selectivity to DBT of $\beta$-CDP}

As everyone knows, the desulfurization selectivity of desulfurizer is important, so the desulfurization selectivity of $\beta$-CDP for DBT was studied.

The desulfurization experiment about the selectivity to DBT was carried out as follows. Firstly, $\beta$-CDP and $n$-heptane solution of sulfides were added to a $25 \mathrm{~mL}$ vial, and then the mixture was stirred by magneton for $2 \mathrm{~h}$ to reach the equilibrium. The result of sulfur removal of $\beta$-CDP for different sulfides was presented in Fig. 8.

As an interesting result shown in Fig. 8, the total desulfurization rate was $58.14 \%$, and meanwhile the desulfurization rate of DBT was $54.76 \%$. It could be clearly seen that DBT removal contributed about $94 \%$ to the total sulfur removal, indicating that $\beta$-CDP has an excellent selectivity to DBT. Based on this result, probably DBT could be produced and enriched as a by-product in desulfurization by $\beta$-CDP, which would be a meaningful process for practical application. The reason for the results also lies in that the cavities of $\beta$-CDP have suitable cavity size for DBT and the excellent electronic effects between $\beta$-CDP with DBT. And the good synergetic effect of adjacent cyclodextrin cavities in $\beta$-CDP may also play an important role in that.

In addition, Th, TP, EPS and BT were chosen as references to investigate the selectivity of $\beta$-CDP. Two kinds of model oil samples were prepared, and the concentration ratios of different sulfides were $1: 1: 1: 1: 1$ and $6: 1: 1: 1: 1$ (DBT : BT : Th : TP : EPS), respectively. To better illustrate the effect of other sulfides on the desulfurization selectivity to DBT of $\beta$-CDP, the desulfurization efficiency in Table $\mathrm{S} 1 \uparrow$ was calculated according to the listed equation (E1 in ESI†े). 


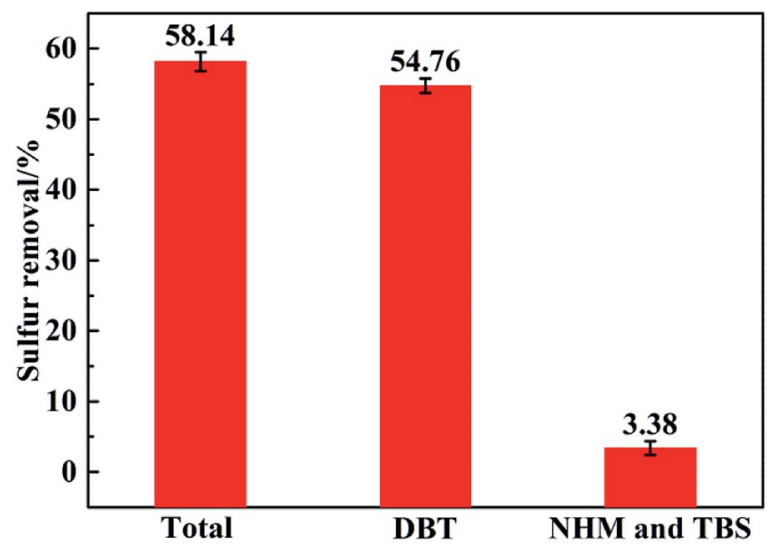

Fig. 8 The desulfurization selectivity to DBT of $\beta$-CDP. Desulfurization conditions: temperature $=25^{\circ} \mathrm{C}$, time $=2 \mathrm{~h}$, mass ratio of $\beta$-CDP to $n$ heptane solution of mixed-sulfides is $1: 20$. All results were obtained in triplicate, and standard deviation is indicated by the error bars.

From Table $\mathrm{S} 1, \dagger$ it can be seen that, for experiment A, the DBT removal could reach $91.4 \%$. At the same time, for experiment $\mathrm{B}$, the DBT removal could reach $87.9 \%$. The results suggest that $\beta$-CDP has a good selectivity for DBT, which is consistent with the result obtained in the DBT, NHM and TBS experiment (Fig. 8).

\subsection{Regeneration performance of $\beta$-CDP}

The recycling of the desulfurizer is a key issue for practical application. For the regeneration performance of $\beta$-CDP, $\beta$-CDP was firstly deactivated using $n$-heptane solution of DBT, until its desulfurization efficiency of DBT with the sulfur content of $100 \mu \mathrm{g} \mathrm{g}^{-1}$ below $10 \%$. After that, the deactivated $\beta$-CDP was regenerated with the ethanol. The deactivated $\beta$-CDP and ethanol with mass ratio of 1 : 50 were stirred in a flask at $60^{\circ} \mathrm{C}$ for $30 \mathrm{~min}$. This regeneration procedure was repeated four times with ethanol. The regenerated $\beta$-CDP was tested in the typical desulfurization procedure according to procedure showed in 2.4. The results were presented in Fig. $\mathrm{S} 3 . \dagger$ The results illustrated that the desulfurization performance of $\beta$-CDP was kept almost the same after being regenerated four times and the recyclability of $\beta$-CDP as a novel desulfurizer was excellent. Moreover, the regeneration method of $\beta$-CDP is easy and its cost is low.

\subsection{Adsorption kinetic studies of $\beta$-CDP for DBT}

To better understand the mechanism of the desulfurization process between DBT and $\beta$-CDP, adsorption kinetic was investigated. And the obtained data was analyzed by the pseudosecond order. The linear form of the model was given as:

$$
t / q_{t}=t / q_{\mathrm{e}}+1 / k_{2} q_{\mathrm{e}}^{2}
$$

where $q_{t}$ and $q_{\mathrm{e}}\left(\mathrm{mg} \mathrm{g}^{-1}\right)$ were the amount of DBT adsorbed per $\mathrm{g}$ of sorbent at contact time and equilibrium time $t$ (min), respectively. And $k_{2}\left(\mathrm{~g} \mathrm{mg}^{-1} \mathrm{~min}^{-1}\right)$ was the rate constant of the second-order kinetic model.

The plot of $\left(t / q_{\mathrm{e}}\right)$ versus time was shown in Fig. S4, $\dagger$ and a good linear relation was observed according to $R^{2}(0.9998)$. At the same time, $k_{2}$ and $q_{\mathrm{e}}$ were also calculated, and they were $0.6389 \mathrm{~g} \mathrm{mg}^{-1} \mathrm{~min}^{-1}$ and $2.8425 \mathrm{mg} \mathrm{g}^{-1}$, respectively.

\subsection{Mechanism of molecular recognition of $\beta$-CDP for DBT}

Fig. 9 showed that the XRD patterns of the fresh $\beta$-CDP, used $\beta$ CDP and DBT. The results demonstrated that the used $\beta$-CDP has almost similar diffraction patterns to fresh $\beta$-CDP, certifying good structural stability of $\beta$-CDP in desulfurization process. Furthermore, the diffraction signals of DBT were not observed in diffraction pattern of used $\beta$-CDP, indicating that most DBT did not form aggregation on the surface of $\beta$-CDP and they probably form inclusion complex by efficient molecular recognition.

In order to investigate the mechanism of DBT desulfurization by $\beta$-CDP, ${ }^{1} \mathrm{H}$ NMR spectras of relevant substances were carried out and given in Fig. 10 and 11, respectively. Furthermore, the chemical shifts of different protons of $\beta$-CDP and inclusion complex, DBT and inclusion complex were summarized in Tables 2 and 3, respectively. The great chemical shifts were ascribed to the signals of $\mathrm{H}-3, \mathrm{H}-6$ and $\mathrm{H}-5$ of $\beta$-CDP, which

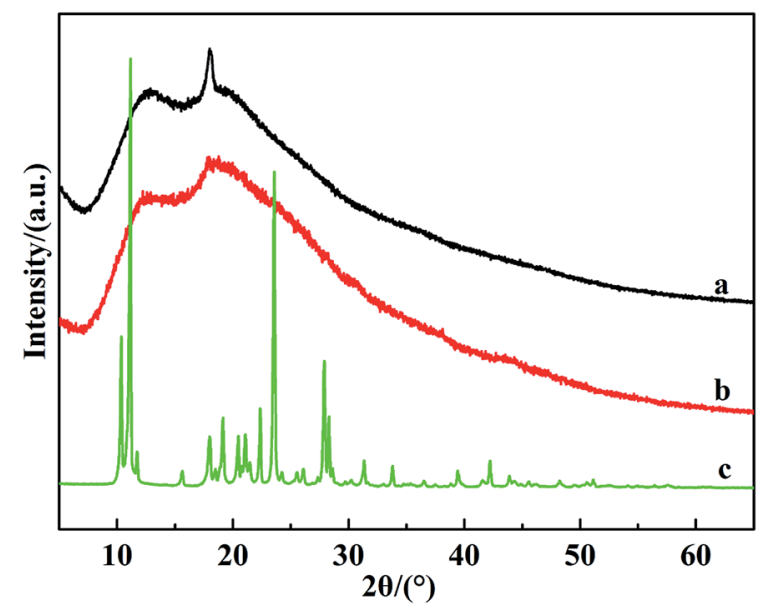

Fig. 9 XRD patterns of (a) fresh $\beta$-CDP, (b) used $\beta$-CDP and (c) DBT.

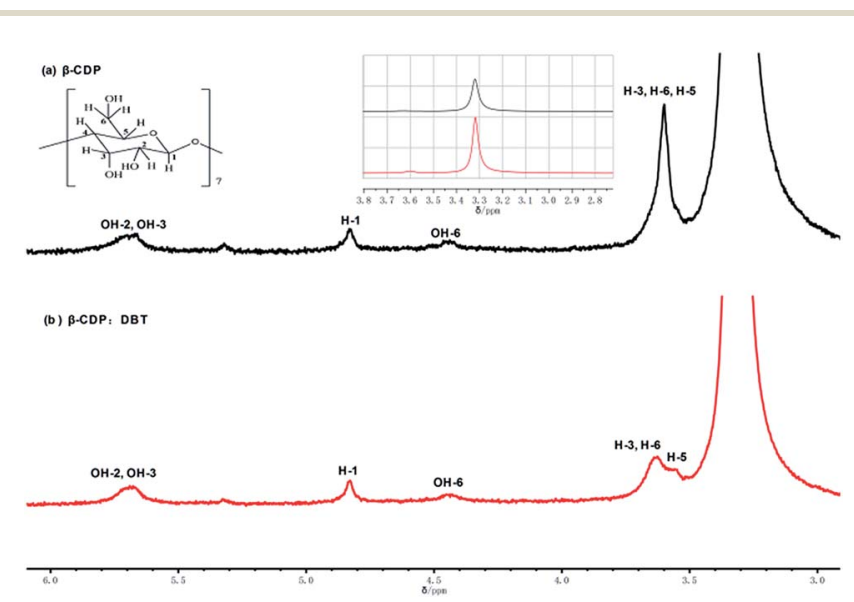

Fig. $10{ }^{1} \mathrm{H}$ NMR (DMSO- $d_{6}$ ) spectra of (a) fresh $\beta$-CDP and (b) used $\beta$ CDP (partly enlarged). 


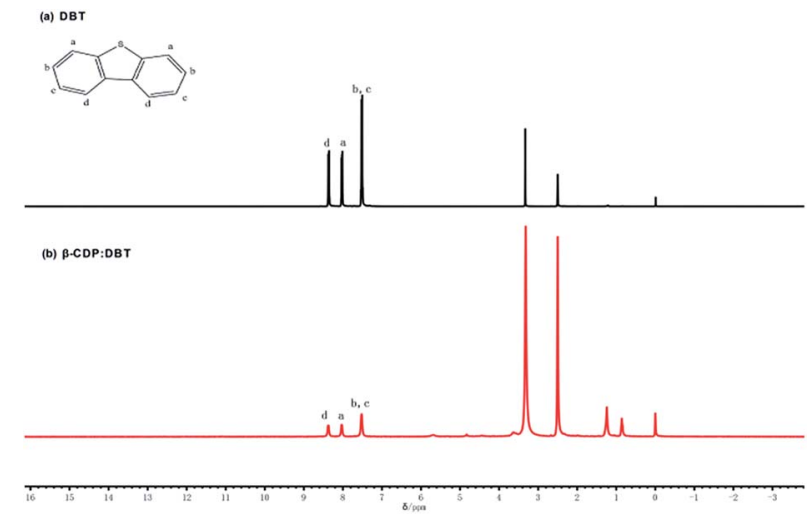

Fig. $11{ }^{1} \mathrm{H}$ NMR (DMSO- $d_{6}$ ) spectra of (a) DBT and (b) used $\beta$-CDP.

Table 2 Variation in ${ }^{1} \mathrm{H}-\mathrm{NMR}$ proton chemical shift of $\beta$-CDP and inclusion complex in DMSO- $d_{6}$

\begin{tabular}{lcccc}
\hline & OH-2,3 & OH-6 & H-3,6 & H-5 \\
\hline$\delta(\beta-\mathrm{CDP}: \mathrm{DBT}) / \mathrm{ppm}$ & 5.6773 & 4.4519 & 3.6030 & 3.6030 \\
$\delta(\beta-\mathrm{CDP}) / \mathrm{ppm}$ & 5.6922 & 4.4363 & 3.6524 & 3.6233 \\
$\Delta \delta / \mathrm{ppm}$ & 0.0149 & 0.0156 & 0.0494 & 0.0203 \\
\hline
\end{tabular}

Table 3 Variation in ${ }^{1} \mathrm{H}$-NMR proton chemical shift of inclusion complex and DBT in DMSO- $d_{6}$

\begin{tabular}{llll}
\hline & $\mathrm{H}-2,10$ & $\mathrm{H}-5,13$ & $\mathrm{H}-1,6,11,12$ \\
\hline$\delta(\beta-\mathrm{CDP}: \mathrm{DBT}) / \mathrm{ppm}$ & 8.3648 & 8.0275 & 7.5153 \\
$\delta(\mathrm{DBT}) / \mathrm{ppm}$ & 8.3747 & 8.0359 & 7.5258 \\
$\Delta \delta / \mathrm{ppm}$ & 0.0099 & 0.0084 & 0.0075
\end{tabular}

were shifted from 3.6030 to 3.6524 and 3.6030 to 3.6233 , respectively. It lies in that $\mathrm{H}-3$ and $\mathrm{H}-5$ were belonged to the protons in the interior of $\beta$-CDP cavities and the inclusion complex of DBT with $\beta$-CDP probably have larger effect on the protons which located in the interior of $\beta$-CDP cavities. As Table 3 showed, the proton chemical shifts of DBT were much smaller than those of $\beta$-CDP, which probably because that the shielding effect of DBT to $\beta$-CDP was larger than that of $\beta$-CDP to DBT. And the result also confirmed that $\beta$-CDP formed inclusion complex with $\mathrm{DBT}^{58,59}$ and DBT was mainly removed in the form of inclusion complex.

Fig. $\mathrm{S} 5 \dagger$ showed the nitrogen adsorption and desorption isotherms of $\beta$-CDP before and after desulfurization of DBT. The BET surface areas of fresh and used $\beta$-CDP were 156 and $129 \mathrm{~m}^{2} \mathrm{~g}^{-1}$, respectively. It's obvious that the BET surface area decreased $27 \mathrm{~m}^{2} \mathrm{~g}^{-1}$, which might be due to the adsorption of DBT on the surface of $\beta$-CDP and the inclusion of DBT by $\beta$-CDP. In the meantime, the decrease in BET surface area was small, and it also indicated that the DBT was mainly removed in the form of inclusion complex by molecular recognition. Moreover, Fig. S5 $\uparrow$ showed that the BET surface area of $\beta$-CDP decreased slightly after desulfurization, while the surface area of most materials used in desulfurization by adsorption process

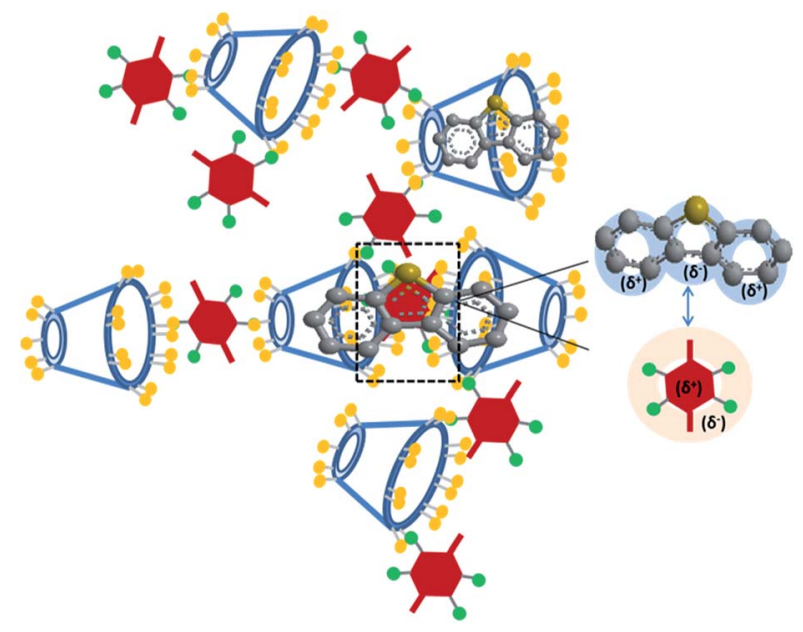

Scheme 1 Molecular recognition mechanism of the removal of DBT by $\beta$-CDP.

generally decreased more than $100 \mathrm{~m}^{2} \mathrm{~g}^{-1}$ and even more than $300 \mathrm{~m}^{2} \mathrm{~g}^{-1}$, as reported by Zhang etc. ${ }^{60}$ and Xiao, etc., ${ }^{61}$ respectively.

FTIR spectra of fresh and used $\beta$-CDP were presented in Fig. S6. $\dagger$ It showed that the adsorption bands of used $\beta$-CDP were similar to those of fresh $\beta$-CDP and no new adsorption bands appearing in spectra of used $\beta$-CDP, which is consistent with the reported results. ${ }^{62}$ Combined with the XRD (Fig. 9), NMR results (Fig. 10) and references, it could be concluded that few DBT was absorbed on the surface of $\beta$-CDP and most DBT is included in $\beta$-CD cavity by molecular recognition.

Combined the results showed above, the mechanism of the removal of DBT by $\beta$-CDP was put forward in Scheme 1. It indicated that DBT and $\beta$-CDP could form inclusion complex and DBT was mainly removed in the form of inclusion complex by molecular recognition. In the molecular recognition, the main interaction was host-guest inclusion due to the suitable cavity size of $\beta$-CDP cavities towards DBT and high synergetic effect of adjacent cyclodextrin cavities, which was confirmed by NMR, FTIR and BET.

Besides, the electronic interactions between electrondeficient groups in $\beta$-CDP and electron-rich DBT might strengthen the inclusion effects and be helpful to improve the desulfurization performance for DBT..$^{63,64}$

In a word, the cyclodextrin polymer shows high desulfurization efficiency and selectivity by the molecular recognition as a novel method.

\section{Conclusions}

A series of CDPs were synthesized and they were used for removing different sulfides, which hasn't been reported previously. The results showed that different polymers had a higher desulfurization efficiency for sulfides with aromatic ring structure than those with aliphatic chain structure. The $\beta$-CDP exhibited the best desulfurization performance among CDPs, in particular, it had an excellent selectivity for removing DBT. The 
proper temperature and the mass ratio of $\beta$-CDP to $n$-heptane solution of DBT were $25{ }^{\circ} \mathrm{C}$ and $1: 20$, respectively. Meanwhile, the $\beta$-CDP displayed good performance for deep desulfurization, maybe due to the inclusion and electronic effect between $\beta$-CDP and DBT by excellent molecular recognition. Furthermore, the samples were characterized by various characterization measurements, and the results showed that $\beta$-CDP had the advantages of wide applicable temperature range. Simultaneously, the structure of $\beta$-CDP maintained almost unchanged before and after desulfurization, which was confirmed by XRD, ${ }^{1} \mathrm{H}$ NMR and FTIR.

Based on the above results, the molecular recognition mechanism was proposed and it revealed that $\beta$-CDP had more suitable cavity size and electronic effects for removing DBT in the form of inclusion complex.

\section{Conflict of interest}

The authors declare no competing financial interest.

\section{Acknowledgements}

This work was financially supported by the National Natural Science Foundation of China (Grant 21376265) and the Fundamental Research Funds for the Central Universities (Grants no. 15CX02029A).

\section{References}

1 Y. S. Shen, P. W. Li, X. H. Xu and H. Liu, RSC $A d v .$, 2012, 2, 1700.

2 M. Armaghan, M. M. Amini, H. R. Khavasi, W. H. Zhang and S. W. Ng, RSC Adv., 2016, 6, 85381.

3 J. H. Kou, C. H. Lu, W. H. Sun, L. Zhang and Z. Z. Xu, ACS Sustainable Chem. Eng., 2015, 3, 3053.

4 A. K. Tuxen, H. G. Füchtbauer, B. Temel, B. Hinnemann, H. Topsøe, K. G. Knudsen, F. Besenbacher and J. V. Lauritsen, J. Catal., 2012, 295, 146.

5 R. Javadli and A. Klerk, Energy Fuels, 2012, 26, 594.

6 J. Xiao, L. M. Wu, Y. Wu, B. Liu, L. Dai, Z. Li, Q. B. Xia and H. X. Xi, Appl. Energy, 2014, 113, 78.

7 C. S. Song and X. L. Ma, Appl. Catal., B, 2003, 41, 207.

8 F. Subhan, B. S. Liu, Y. Zhang and X. G. Li, Fuel Process. Technol., 2012, 97, 71.

9 U. Maity, J. K. Basu and S. Sengupta, Fuel Process. Technol., 2014, 121, 119.

10 A. Akbari, M. Omidkhah and J. T. Darian, Ultrason. Sonochem., 2015, 23, 231.

11 M. Sharma, P. Sharma and J. N. Kim, $R S C A d v ., 2013$, 3, 10103.

12 W. S. Zhu, B. L. Dai, P. W. Wu, Y. H. Chao, J. Xiong, S. H. Xun, H. P. Li and H. M. Li, ACS Sustainable Chem. Eng., 2015, 3, 186.

13 W. Zhang, H. Zhang, J. Xiao, Z. X. Zhao, M. X. Yu and Z. Li, Green Chem., 2014, 16, 211.

14 M. Chamack, A. R. Mahjoub and H. Aghayan, Chem. Eng. J., 2014, 255, 686.
15 Y. W. Shi, X. W. Zhang, L. Wang and G. Z. Liu, AIChE J., 2014, 60, 2747.

16 Y. Zhu, Z. Hua, X. X. Zhou, Y. D. Song, Y. Gong, J. Zhou, J. J. Zhao and J. L. Shi, RSC Adv., 2013, 3, 4193.

17 L. F. Wang and R. T. Yang, AIChE J., 2013, 59, 29.

18 C. Asumana, G. Yu, X. Li, J. J. Zhao, G. Liu and X. C. Chen, Green Chem., 2010, 12, 2030.

19 H. S. Gao, C. Guo, J. M. Xing, J. M. Zhao and H. Z. Liu, Green Chem., 2010, 12, 1220.

20 Z. Li, C. P. Li, Y. S. Chi, A. L. Wang, Z. D. Zhang, H. X. Li, Q. S. Liu and U. Welz-Biermann, Energy Fuels, 2012, 26, 3723.

21 H. P. Li, Y. H. Chang, W. S. Zhu, W. Jiang, M. Zhang, J. X. Xia, S. Yin and H. M. Li, J. Phys. Chem. B, 2015, 119, 5995.

22 R. Abro, A. A. Abdeltawab, S. S. Al-Deyab, G. R. Yu, A. B. Qazi, S. R. Gao and X. C. Chen, RSC Adv., 2014, 4, 35302.

23 L. Gonsalvesh, S. P. Marinov, M. Stefanova, R. Carleer and J. Yperman, Fuel, 2013, 103, 1039.

24 Y. G. Li, W. L. Li, H. S. Gao, J. M. Xing and H. Z. Liu, J. Chem. Technol. Biotechnol., 2011, 86, 246.

25 V. P. Ananikov, N. V. Orlov, S. S. Zalesskiy, I. P. Beletskaya, V. N. Khrustalev, K. Morokuma and D. G. Musaev, J. Am. Chem. Soc., 2012, 134, 6637.

26 W. M. Yang, L. K. Liu, W. Zhou, W. Z. Xu, Z. P. Zhou and W. H. Huang, Appl. Surf. Sci., 2012, 258, 6583.

27 L. Qin, W. P. Shi, W. F. Liu, Y. Z. Yang, X. G. Liu and B. S. Xu, RSC Adv., 2016, 6, 12504.

28 C. S. Song, Catal. Today, 2003, 86, 211.

29 B. Castro, M. J. Whitcombe and E. N. Vulfson, Anal. Chim. Acta, 2001, 435, 83-90.

30 J. Aburto, A. Mendez-Orozco and S. L. Borgne, Chem. Eng. Process., 2004, 43, 1587.

31 Y. H. Chang, L. Zhang, H. J. Ying, Z. J. Li, H. Lv and P. K. OuYang, Appl. Biochem. Biotechnol., 2010, 160, 593.

32 J. R. Lakkakula and R. W. M. Krause, Nanomedicine, 2014, 9, 877.

33 R. Gharib, H. Greige-Gerges, S. Fourmentin, C. Charcosset and L. Auezova, Carbohydr. Polym., 2015, 129, 175.

34 Z. M. Zhou, X. Li, X. P. Chen, M. Fang and X. Dong, Talanta, 2010, 82, 775.

35 S. Schürch, A. Saxer, S. Claude, R. Tabacchi, B. Trusch and J. Hulliger, J. Chromatogr. A, 2001, 905, 175.

36 M. Ferreira, H. Bricout, A. Sayede, A. Ponchel, S. Fourmentin, S. Tilloy and E. Monflier, Adv. Synth. Catal., 2008, 350, 609.

37 C. J. Zou, P. W. Zha, J. Ge, Y. B. Qin and P. Y. Luo, Fuel, 2013, 104, 635.

38 X. L. Song, L. B. Sun, G. S. He and X. Q. Liu, Chem. Commun., 2011, 47, 650.

39 Y. Sun, D. H. Xia and Y. Z. Xiang, Pet. Sci. Technol., 2008, 26, 2023.

40 Y. Inoue, T. Hakushi, Y. Liu, L. H. Tong, B. J. Shen and D. S. Jin, J. Am. Chem. Soc., 1993, 115, 475.

41 A. Ueno, A. Ikeda, H. Ikeda, T. Ikeda and F. Toda, J. Org. Chem., 1999, 64, 382.

42 J. M. Choi, E. Cho, B. Lee, D. Jeong, Y. Choi, J. H. Yu and S. Jung, Carbohydr. Polym., 2016, 151, 40. 
43 J. M. Benito, M. Gómez-García, C. O. Mellet, I. Baussanne, J. Defaye and J. M. G. Fernández, J. Am. Chem. Soc., 2004, 126, 10355.

44 T. Hishiya, H. Asanuma and M. Komiyama, J. Am. Chem. Soc., 2002, 124, 570.

45 M. R. Jong, R. M. A. Knegtel, P. D. J. Grootenhuis, J. Huskens and D. N. Reinhoudt, Angew. Chem., Int. Ed., 2002, 41, 1004. 46 X. Ren, Y. Xue, J. Liu, K. Zhang, J. Zheng, G. Luo, C. Guo, Y. Mu and J. Shen, ChemBioChem, 2002, 3, 356.

47 S. Matsumura, S. Sakamoto, A. Ueno and H. Mihara, Chem.Eur. J., 2000, 6, 1781.

48 Y. Liu, C. C. You and B. Li, Chem.-Eur. J., 2001, 7, 1281.

49 A. Alsbaiee, B. J. Smith, L. L. Xiao, Y. H. Ling, D. E. Helbling and W. R. Dichtel, Nature, 2016, 529, 190.

50 Z. X. Liang, W. M. Chen, J. G. Liu, S. L. Wang, Z. H. Zhou, W. Z. Li, G. G. Sun and Q. Xin, J. Membr. Sci., 2004, 233, 39.

51 K. Srinivasan, K. Sivakymar and T. Stalin, Carbohydr. Polym., 2014, 113, 577.

52 E. M. M. Del Valle, Process Biochem., 2004, 39, 1033.

53 J. Szejtli, Chem. Rev., 1998, 98, 1743.
54 C. Kwak, J. J. Lee, J. S. Bae, K. Choi and S. H. Moon, Appl. Catal., A, 2000, 200, 233.

55 D. S. Zhao, Y. N. Wang, E. H. Duan and J. Zhang, Fuel Process. Technol., 2010, 91, 1803.

56 M. X. Li, Z. Y. Zhou, F. Zhang, W. S. Chai, L. L. Zhang and Z. Q. Ren, AIChE J., 2016, 62, 4023.

57 H. Y. Lü, P. C. Li, C. L. Deng, W. Z. Ren, S. N. Wang, P. Liu and H. Zhang, Chem. Commun., 2015, 51, 10703.

58 M. Liu, A. J. Chen, Y. Wang, C. M. Wang, B. Q. Wang and D. Z. Sun, Food Chem., 2015, 168, 270.

59 W. Z. Li, X. Y. Liu, Q. F. Yang, N. Zhang, Y. D. Du and H. P. Zhu, Food Chem., 2015, 184, 99.

60 Z. F. Zhang, B. S. Liu, F. Wang, W. S. Wang, C. Xia, S. Zheng and R. Amin, Appl. Surf. Sci., 2014, 313, 961.

61 Y. H. Xiao, S. D. Wang, D. Y. Wu and Q. Yuan, Sep. Purif. Technol., 2008, 59, 326.

62 X. W. Zhang, D. N. Wu, J. Lai, Y. Lu, Z. N. Yin and W. Wu, J. Pharm. Sci, 2009, 98, 665.

63 L. Liu and Q. X. Guo, J. Inclusion Phenom. Macrocyclic Chem., 2002, 42, 1.

64 H. J. Schneider, Angew. Chem., Int. Ed., 2009, 48, 3924. 